\title{
ГЕОХИМИЯ РЕДКИХ ЭЛЕМЕНТОВ (LA-ICP-MS) В МОНАЦИТЕ ИЗ РУДОПРОЯВЛЕНИЯ ИЧЕТЪЮ, СРЕДНИЙ ТИМАН
}

Скублов С.Г. ${ }^{1,2}$, Красоткина А.О. ${ }^{2}$, Макеев А.Б. ${ }^{3}$, Томсен Т.Б. ${ }^{4}$, Серре С.Х. ${ }^{4}$, Абдрахманов И.А. ${ }^{2}$

${ }^{1}$ Институт геологии и геохронологии докембрия РАH, Санкт-Петербург, skublov@yandex.ru

${ }^{2}$ Горный университет, Санкт-Петербург

${ }^{3}$ Институт геологии рудных месторождений, петрографии, минералогии и геохимии, Москва, abmakeev@mail.ru

${ }^{4}$ Геологическая служба Дании и Гренландии, Копенгаген, Дания

Пижемское месторождение титана и полиминеральное проявление Ичетъю, расположенные на Среднем Тимане, в перспективе могут быть крайне востребованными как в отношении гигантских ресурсов титана и кварцевых песчаников стекольного качества, так и в возможном расширении перечня перспективных полезных компонентов (редкие металлы - Y, Zr, Nb, REE, алмазы и др.) [5 и др.]. Полиминеральное алмаз-золото-редкометалльно-редкоземельно-титановое рудопроявление Ичетью представляет собой горизонт конглобрекчиевых пород со сложной пятнистоструйчато-линзовидной морфологией тел и выдержанной мощностью от 0.2 до 1.5 м. Породы рудопроявления представлены светло-серыми кварцевыми песчаниками, гравелитами, конгломератами и конглобрекчиями, залегающими между двумя мощными толщами в основании пижемских мономинеральных кварцевых песчаников стекольного качества и выше ильменит-лейкоксен-кварцевой малоручейской титаноносной толщи Пижемского месторождения Среднего Тимана. Породы рудопроявления Ичетью отличаются разнообразием минерального состава: диагностировано более 50 минералов, главные из которых: кварц, рутил, анатаз, ниобиевый рутил, ильменит, циркон, монацит, колумбит, гранаты, хромшпинелиды, турмалин, ставролит, золото с примесью серебра, кривогранные алмазы уральско-бразильского типа [4].

Проведено исследование геохимии монацита из 19 шлиховых проб, отобранных из пород рудопроявления Ичетью в бассейне рек Пижма, Умба и Средняя.

\section{Аналитическая методика}

Предварительное исследование состава монацита, зерна которого были смонтированы в эпоксидной смоле в стандартных шайбах, проведено методом SEM-EDS (JEOL JSM-6510LA с энергодисперсионной приставкой JED-2200) в ИГГД РАН. Содержание 30 редких элементов определено методом LA-ICP-MS в лаборатории Геологической службы Дании и Гренландии (GEUS). Использовался NWR213 Nd:YAG лазерная система, соединенная с масс-спектрометром ELEMENT 2. Кратер диаметром около 40 мкм ставился в центре зерна в место, свободное от микровключений и трещин. Стекла NIST 612 и 614 и монацит-стандарт Bananeira использовались для оценки качества определения содержания редких элементов. В итоге было проанализировано 84 зерна монацита, средний состав которых приведен в таблице.

\section{Результаты}

Практически в каждой пробе выделено две разновидности монацита, достигающего в поперечнике 1-2 мм. Преобладает непрозрачный серый (до черного) глобулярный монацит, неодимцериевый по составу. Зерна этого типа линзовидные, со следами растворения и замещения. Высокая степень окатанности зерен свидетельствует о дальности их переноса. Характерно замещение порового пространства кварцем и флоренситом [3]. В отечественной литературе монацит с такими характеристиками называют куларитом $[2,6]$, однако, за рубежом этот термин не получил распространения и в настоящее время не используется.

Монацит обычного желтоватого оттенка представлен в подчиненном количестве, по составу он лантан-цериевый. Удлиненные кристаллы характеризуются однородным монолитным внутренним строением, а их относительно хорошая сохранность свидетельствует о близком коренном источнике [3]. 
Таблица. Обобщенная характеристика состава монацита из проявления Ичетъю.

\begin{tabular}{|c|c|c|c|c|c|c|c|c|c|c|}
\hline \multirow{2}{*}{$\begin{array}{l}\text { Эле- } \\
\text { мент }\end{array}$} & \multicolumn{5}{|c|}{ Куларит (серый монацит) $(\mathrm{n}=58)$} & \multicolumn{5}{|c|}{ Желтый монацит (n = 26) } \\
\hline & median & mean & $\mathrm{sd}$ & $\min$ & $\max$ & median & mean & sd & $\min$ & $\max$ \\
\hline $\mathrm{Al}$ & 10250 & 10639 & 5146 & 2600 & 34000 & 0.13 & 9.71 & 18.9 & b.d.1. & 81.0 \\
\hline $\mathrm{Si}$ & 19500 & 23006 & 12717 & 8990 & 71000 & 143 & 261 & 488 & b.d.l. & 2310 \\
\hline $\mathrm{Ca}$ & 14950 & 16548 & 6482 & 3940 & 34000 & 9695 & 10621 & 6884 & 1455 & 33400 \\
\hline $\mathrm{Ti}$ & 2800 & 2802 & 1259 & 550 & 6100 & 0.23 & 0.37 & 0.42 & b.d.l. & 1.40 \\
\hline $\mathrm{Mn}$ & 12.3 & 20.3 & 19.0 & 4.03 & 96.0 & 0.55 & 2.14 & 4.04 & b.d.l. & 19.3 \\
\hline $\mathrm{Fe}$ & 6665 & 11904 & 12685 & 2190 & 60200 & 45.5 & 289 & 594 & b.d.l. & 2850 \\
\hline $\mathrm{Rb}$ & 21.1 & 22.8 & 11.5 & 4.00 & 69.0 & 0.22 & 0.22 & 0.13 & 0.02 & 0.49 \\
\hline $\mathrm{Sr}$ & 2260 & 2407 & 886 & 672 & 4910 & 1890 & 1948 & 1296 & 209 & 6640 \\
\hline $\mathrm{Y}$ & 6565 & 6495 & 686 & 4810 & 7780 & 1026 & 1176 & 909 & 79.9 & 3090 \\
\hline $\mathrm{Zr}$ & 63.5 & 64.9 & 17.2 & 34.9 & 104 & 0.24 & 0.37 & 0.40 & b.d.l. & 1.28 \\
\hline $\mathrm{Nb}$ & 19.0 & 24.2 & 18.3 & 6.70 & 98.0 & 0.15 & 0.17 & 0.12 & 0.02 & 0.38 \\
\hline $\mathrm{Ba}$ & 113 & 122 & 51.2 & 42.8 & 290 & 29.0 & 43.7 & 44.8 & 1.81 & 176 \\
\hline $\mathrm{La}$ & 73100 & 82010 & 33660 & 32900 & 201000 & 203300 & 203615 & 47951 & 95800 & 324000 \\
\hline $\mathrm{Ce}$ & 234500 & 231248 & 35750 & 134400 & 321000 & 260500 & 266127 & 22132 & 227000 & 308000 \\
\hline $\operatorname{Pr}$ & 38800 & 38286 & 3176 & 31100 & 44400 & 23350 & 25269 & 5492 & 19100 & 38600 \\
\hline $\mathrm{Nd}$ & 198950 & 197622 & 34736 & 108600 & 275000 & 79850 & 86077 & 28733 & 52100 & 157100 \\
\hline $\mathrm{Sm}$ & 45700 & 48125 & 20550 & 13200 & 99300 & 5210 & 7352 & 5574 & 2500 & 23990 \\
\hline $\mathrm{Eu}$ & 7295 & 7236 & 2830 & 2070 & 13970 & 951 & 1357 & 1191 & 368 & 5950 \\
\hline $\mathrm{Gd}$ & 22600 & 22109 & 7908 & 7410 & 38200 & 1683 & 2818 & 2986 & 709 & 12900 \\
\hline $\mathrm{Tb}$ & 1555 & 1526 & 358 & 820 & 2300 & 103 & 186 & 214 & 38.6 & 964 \\
\hline Dy & 4150 & 4108 & 622 & 2920 & 5440 & 351 & 529 & 547 & 65.7 & 2590 \\
\hline Ho & 333 & 334 & 39.7 & 249 & 418 & 44.3 & 52.8 & 43.4 & 4.15 & 177 \\
\hline $\mathrm{Er}$ & 424 & 409 & 49.0 & 299 & 495 & 65.5 & 82.3 & 60.8 & 14.1 & 220 \\
\hline $\mathrm{Tm}$ & 27.5 & 26.5 & 3.95 & 18.2 & 35.1 & 3.66 & 5.77 & 5.07 & 0.25 & 18.9 \\
\hline $\mathrm{Yb}$ & 98.9 & 95.5 & 18.6 & 55.7 & 150 & 11.6 & 20.1 & 18.5 & 1.17 & 71.0 \\
\hline $\mathrm{Lu}$ & 6.52 & 6.64 & 1.66 & 3.87 & 14.0 & 0.73 & 1.28 & 1.22 & 0.07 & 4.50 \\
\hline $\mathrm{Hf}$ & 2.59 & 2.87 & 1.01 & 1.62 & 8.30 & 0.03 & 0.04 & 0.03 & b.d.l. & 0.12 \\
\hline $\mathrm{Pb}$ & 518 & 578 & 284 & 174 & 1680 & 143 & 192 & 232 & 12.7 & 1110 \\
\hline Th & 5550 & 6186 & 2898 & 1630 & 13600 & 3490 & 4794 & 5783 & 360 & 27400 \\
\hline $\mathrm{U}$ & 1364 & 1324 & 505 & 160 & 2700 & 1.47 & 3.59 & 6.39 & 0.01 & 26.5 \\
\hline
\end{tabular}

Примечание: содержание элементов приведено в ppm; b.d.l. -ниже порога чувствительности.

На тройной диаграмме La-Ce-Nd точки составов монацита образуют единый тренд, выпуклый к вершине Се (рис. 1, а). Из трех сравниваемых LREE для большинства зерен максимальное содержание (около 50 отн.\%) установлено для Се, причем это характерно в большей степени для желтого монацита. В некоторых зернах куларита содержание $\mathrm{Nd}$ превышает 50 отн.\%. В желтом монаците относительное содержание La не достигает 50 отн.\%. Спектры распределения REE в монаците из рудопроявления Ичетъю отличаются высокой степенью дифференцированности в области HREE, в большей степени проявленной для желтого монацита. В куларите спектры распределения в об- 
ласти LREE практически горизонтальны (рис. 1, б). В желтом монаците Еu-аномалия не проявлена $\left(\mathrm{Eu} / \mathrm{Eu}^{*}\right.$ в среднем 0.93), а содержание почти всех REE (за исключением La и Ce) меньше, чем в куларите. Содержание Се примерно совпадает для обеих разновидностей монацита. В куларите проявлена слабая отрицательная Еu-аномалия (Eu/Eu* в среднем 0.68). Для куларита установлено «сгущение» спектров распределения REE, в отличие от желтого монацита, в котором содержание HREE заметно варьирует.

Характерной особенностью монацита из рудопроявления Ичетью является крайне низкое содержание Th, для большинства зерен не превышающее 1 мас. \%. В желтом монаците содержание Тh в целом меньше, чем в куларите (рис. 1, в).

Содержание U в желтом монаците экстремально низкое, для большинства зерен оно находится в интервале 0.1-10 ppm. В куларите среднее содержание U составляет около 1300 ppm (таблица).
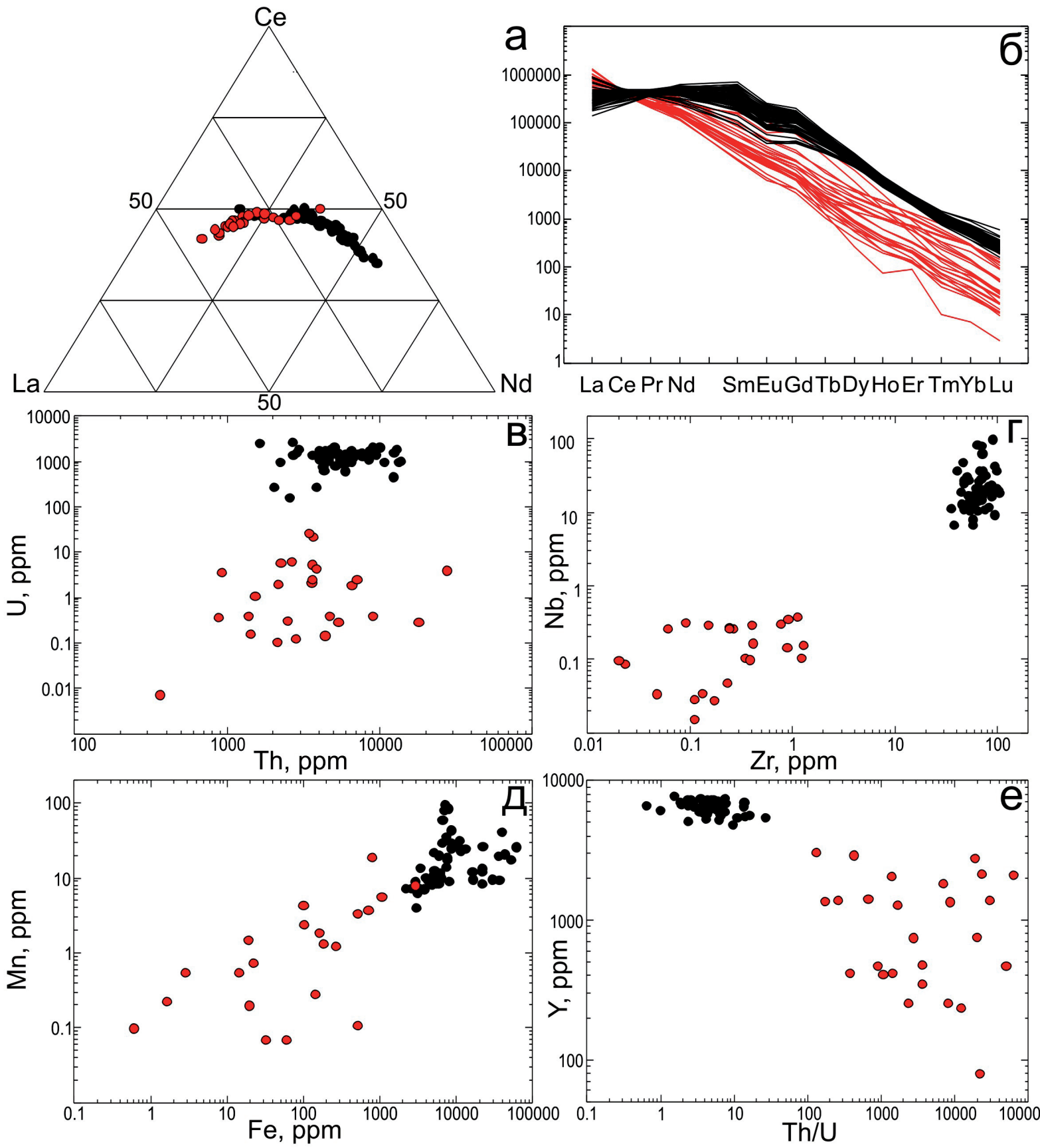

Рис. 1. Состав монацита (черными значками показан куларит, красными значками - желтый монацит). Содержание REE в монаците (на рис. 1, б) нормировано на состав хондрита CI [8]. 
Соответственно, $\mathrm{Th} / \mathrm{U}$ отношение для желтого монацита гораздо выше (минимальное значение составляет 129 , максимальное - 62153), чем у куларита (Th/U отношение варьирует от 0.64 до 26.35 при среднем значении около 5). Поля составов куларита и желтого монацита на диаграмме Th-U (рис. 1, в) не пересекаются, область точек составов куларита отличается большей компактностью, чем в случае с желтым монацитом. Желтый монацит, по сравнению с куларитом, характеризуется пониженным содержанием практически всех элементов, за исключением La и Ce. Для большинства редких элементов точки куларита и желтого монацита не пересекаются на диаграммах (рис. 1, г-е), а поля составов куларита отличаются компактностью по сравнению с желтым монацитом.

Главным вопросом является генезис рассматриваемого монацита. В первую очередь, по крайне низкому содержанию Th, а также другим геохимическим признакам - пониженному содержанию ряда редких элементов, отсутствию заметной отрицательной Еu-аномалии, и куларит, и желтый монацит относятся к гидротермальному монациту [10]. Рядом исследователей [9 и др.] куларит рассматривается не как аутигенный минерал россыпей, а как результат перекристаллизации монацита из иных источников под воздействием флюида. Установлено, что под воздействием флюида при температурах около $300^{\circ} \mathrm{C}$ и ниже происходит образование вторичной гидротермальной генерации монацита и некоторым повышением в нем содержания La, Ce и $\mathrm{Nd}$ при значительном понижении $\mathrm{Th}, \mathrm{U}, \mathrm{Y}, \mathrm{Pb}$ и Si [11]. Описаны случаи, когда флюид в условиях зеленосланцевой фации приводит к значительному перераспределению Y и REE из монацита в сосуществующий апатит [7]. Для куларита из рудопроявления Ичетъю (карьер у скалы Золотой Камень) была установлена зональность, заключающаяся в повышении от центра зерна к краю содержания La и Cе и понижении - Nd [1]. Подобная зональность может быть объяснена различной подвижностью и фракционированием REE в процессе их взаимодействия с гидротермальными растворами.

Таким образом, для рудопроявления Ичетъю установлены два типа гидротермального монацита, отличающихся по составу и, вероятно, возрасту: La-Cе монацит желтого цвета и Nd-Ce куларит (серый монацит). Последний участвовал в процессе лейкоксенизации ильменита (возможно, они с ильменитом составляли единую первичную минеральную ассоциацию). В процессе перемещения к поверхности два типа монацита были совмещены и теперь составляют единую минеральную ассоциацию в алмазоносных конглобрекчиях рудопроявления Ичетъю.

\section{Литература}

1. Колонин Г.Р., Широносова Г.П., Швецова И.В. Зональное распределение главных РЗЭ в метаморфогенном монаците (куларите) и возможности термодинамической оценки условий его образования // Вестник Отделения наук о Земле РАН. 2009. № 1 (27).

2. Кременецкий А.А. Новый геолого-промышленный тип редкоземельных россыпей // Разведка и охрана недр. 1993. № 3. С. 15-19.

3. Макеев А.Б., Вирюс А.А. Монацит проявления Ичетью (состав, морфология, возраст) // Известия высших учебных заведений. Геология и разведка. 2013. № 3. С. 10-15.

4. Макеев А.Б., Дудар В.А. Минералогия алмазов Тимана. СПб.: Наука. 2001. 336 с.

5. Макеев А.Б., Скублов С.Г. Иттриево-редкоземельные цирконы Тимана: геохимия и промышленное значение // Геохимия. 2016. № 9. С. 821-828.

6. Некрасов И.Я., Некрасова Р.А. Куларит - аутигенная разновидность монацита // Докл. АН СССР. 1983. T. 268. № 3. C. 688-693.

7. Harlov D.E., Andersson U.B., Förster H.J., Nyström J.O., Dulski P., Broman C. Apatite-monazite relations in the Kiirunavaara magnetite-apatite ore, northern Sweden // Chemical Geology. 2002. V. 191. P. 47-72.

8. McDonough W.F., Sun S.S. The composition of the Earth // Chemical Geology. 1995. V. 120. P. 223-253.

9. Read D., Cooper D.C. McArthur J.M. The composition and distribution of nodular monazite in the Lower Palaeozoic rocks of Great Britain // Mineralogical Magazine. 1987. V. 51. P. 271-280.

10. Schandl E.S., Gorton M.P. A textural and geochemical guide to the identification of hydrothermal monazite: criteria for selection of samples for dating epigenetic hydrothermal ore deposits // Economic Geology. 2004. V. 99. P. 1027-1035.

11. Seydoux-Guillaume A.M., Montel J.M., Bingen B., Bosse V., De Parseval P., Paquette J.L., Janots E., Wirth R. Low-temperature alteration of monazite: Fluid mediated coupled dissolution-precipitation, irradiation damage, and disturbance of the U-Pb and Th-Pb chronometers // Chemical Geology. 2012. V. 330. P. 140-158. 